
(QJPS)

Vol. 23, No.04, pp. $31-33$, Year-2018

\title{
Study of Shigella flexneri via traditional-bacterial isolation, PCR-sequencing identification, and phylogenetic tree analysis in Al-Diwaniyah City, Iraq
}

\author{
Alaa Abdelkadhim Jawad \\ Department of Microbiology and Parasitology, College of Veterinary Medicine, University of Al-Qadisiyah, Diwaniyah, Iraq \\ Email: alaa.jawad@qu.edu.iq
}

DOI: $10.29350 /$ jops.2018.23.4.910

\begin{abstract}
:
The current study intended to isolate and identify Shigella flexneri via traditional bacterial isolation (TBI), PCRsequencing identification (PSI), and phylogenetic tree analysis(PTA) from patients attended Al-Diwaniyah General Teaching Hospital, Al-Diwaniyah City, Iraq. A total of 25 stool samples were collected and subjected to the above mentioned techniques. The results of the TBI revealed the presence of $S$. flexneri in these samples. The PCR results confirmed the identification of these bacteria in these samples after a piece, $1256 \mathrm{bp}$, of the $\operatorname{gyr} B$ gene, encodes the subunit B protein of DNA gyrase, was targeted. For the sequencing of 2 samples, the results showed the complete confirmation revealing the correctness of the TBI and the PCR results in identifying these bacteria in the tested samples. The PTA revealed separate distinctive clustering of the sequenced samples in one branch of the phylogenetic tree. The current study enhances the documentation that $S$. flexneri is one of the infectious agents that causes GIT-related infections in the current tested city.
\end{abstract}

KEYWORDS: Shigella flexneri, traditional, isolation, PCR, phylogenetic tree,

\section{INTRODUCTION}

Shigella flexneri is a bacterium characterized by Gramnegative staining and its behaviour as a facultative anaerobe which is a member of the family, Enterobacteriaceae(Jin et al., 2002; Wei et al., 2003). Its belong to a genus that has 4 species, which are S.flexneri, S.boydii, S.sonnei, and $S$.dysenteriae. Moreover, these members are classified according to their biochemical reactions and their O-antigen variations into serotypes leading to the identification of 13 serotypes for the $S$. Flexneri alone (Jennison and Verma, 2004). The communicable disease, shigellosis, caused by these bacteria demonstrates itself with dysenteries in patients. The epithelial layers of the colon and rectum are the main targets for these bacteria leading to acute mucosal inflammation, severe tissue damage, abscess formation, ulceration, watery diarrhea, severe abdominal pain, and dysentery(Bennish, 1991; Taneja and Mewara, 2016). Lack of useful treatment may lead to the development of certain secondary health events such as septicemia, hemolytic uremic syndrome, pneumonia, rectal prolapse, arthralgia, seizures, toxic megacolon, intestinal perforation, electrolyte imbalance, and leukemoid reactions(Williams and Berkley, 2018).This disease is responsible of 1.1 million and over 164 million cases each year of mortalities and morbidities respectively; however, this disease attacks mostly children in countries with poor-health systems(Kotloff et al., 1999). The developing countries are known for the $S$. flexneri serotypes of $1 \mathrm{~b}, 2 \mathrm{a}, 3 \mathrm{a}, 4 \mathrm{a}$ and 6 ; however, industrialized countries are known for the presence of 2a serotype in their patients (Kotloff et al., 1999). The disease is occurred via oral route and predisposed via contaminated water, poor hygiene, malnutrition, and lack of antibiotic useful treatment(Lee et al., 2017).

\section{Materials and Methods 2.1.Sampling}

In the current study, 25 stool sample swabs were collected from GIT patients suffering from diarrhea and immediate cultivation in transporting media such as nutrient media. These samples were transferred to a microbiological Lab in the College of Veterinary Medicine, University of Al-Qadisiyah, Al-Diwaniyah, Iraq.

\subsection{Traditional bacterial isolation \\ 2.2.1. Cultivation}

The samples were grown on Congo red tryptic soy agar plates (Payne and Finkelstein, 1977) that showed red-colored colonies. These colonies were inoculated in $50 \mathrm{ml}$ of Pen assay,antibiotic medium3, broth (Difco Laboratories, Detroit, Mich.) incubated at $37^{\circ} \mathrm{C}$. After $4 \mathrm{hrs}$ of cultivation, log-phase culture at $10 \mathrm{ml}$ was inoculated in $1 \mathrm{~L}$ of Pen assay broth prewarmed to $37^{\circ} \mathrm{C}$. This mixture was incubated overnight at $37^{\circ} \mathrm{C}$ in a shaking incubator(Turbyfill etal., 2000).MacConkey agar, xylose-lysine deoxycholate (XLD) agar, and Salmonella-Shigella (SS) agar were also used for this study.

2- Biochemical tests

Kligler's Iron Agar or Triple Sugar Iron Agar were usedin which Shigella generate a gas-free alkaline slant and acid butt(Hale and Keusch, 1996).SIM, Simmons citrate, and MRVP were also used.

\subsubsection{Genomic DNA extraction}

From the overnight bacterial broth culture, $1.5 \mathrm{ml}$ were centrifuged to pellet the cells in an Eppendorf tube, DNA was extracted according to procedure of bacterial genomic extraction kit (Gene aid company, Taiwan).

\subsubsection{PCR-based technique}

The primers used in the current work were from (Yamamoto and Harayama, 1995), and they are F: GAAGTCATCATGACCGTTCTGCA and R: AGCAGGGTACGGATGTGCGAGCC that target the 
amplification of a piece in the $g y r B$ gene at a length of $1256 \mathrm{bp}$. The reactions involved the use of $100 \mu \mathrm{l}$ of total volume. The components were $5 \mathrm{U}$ of DNA polymerase, $50 \mathrm{mM} \mathrm{KCl}, 10 \mathrm{mM}$ Tris-HCl (pH 8.3), $1.5 \mathrm{mM} \mathrm{MgCl}_{2}$, $0.001 \%$ (wt/vol) gelatin, $200 \mathrm{mM}$ (each) of dNTPs, 10pM of each primer. The thermocycler conditions were $95^{\circ} \mathrm{C}$ for $5 \mathrm{~min}$ as for the initial denaturation step (one cycle), 30 cycles of $\left(96^{\circ} \mathrm{C}\right.$ for $1 \mathrm{~min}$ as for the main denaturation step, $63^{\circ} \mathrm{C}$ for $1 \mathrm{~min}$ as for the annealing, and $72^{\circ} \mathrm{C}$ for $1 \mathrm{~min}$ as for the extension), and $72^{\circ} \mathrm{C}$ for $7 \mathrm{~min}$ as for one cycle for the final extension. Then, $3 \%$ agarose gel electrophoresis was used to run the PCR products.

\subsubsection{Sequencing and Phylogenetic analysis.}

The present work involved sequencing of 2 samples. The phylogenetic tree was generated using MegaX software and following A neighbor-joining analysis (Saitou and Nei, 1987; Tamura et al., 2013).

\section{Results}

\subsection{Conventional detection of Shigella}

The results of the TBI revealed the presence of S. flexneri in these samples. These bacteria appeared as red colonies on the Congo red tryptic soy agar plates.

On the Kligler's Iron Agar and the Triple Sugar Iron Agar, the bacterial growth of the Shigella generated a gas-free alkaline slant and acid butt.

\subsection{PCR-based results}

The PCR results confirmed the identification of these bacteria in these samples after a piece, $1256 \mathrm{bp}$, of the $g y r B$ gene, encodes the subunit B protein of DNA gyrase, was targeted, figure 1.

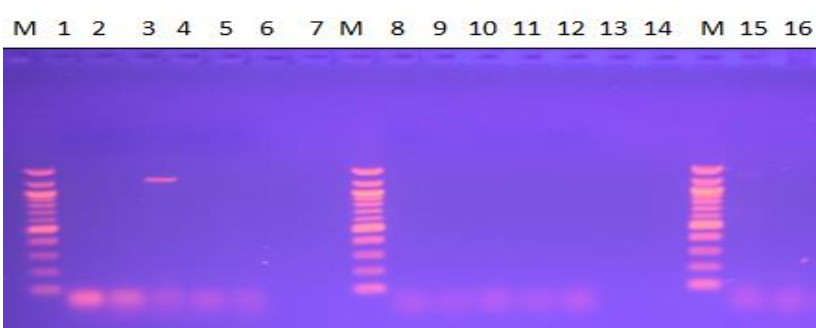

Figure 1: Agarose gel electrophoresis of gyrB amplicon (1265bp) of Shigella, lanes: 3 and 17. M: is the ladder (1500100bp).

\subsection{Sequencing results}

For the sequencing of 2 samples, the results showed the complete confirmation revealing the correctness of the TBI and the PCR results in identifying these bacteria in the tested samples.

\subsection{Phylogenetic-based results}

The PTA revealed separate distinctive clustering of the sequenced samples in one branch of the phylogenetic tree. These isolates are registered in the NCBI-gene Bank under the numbers, MK242204.1 and MK342205.1, figure 2.

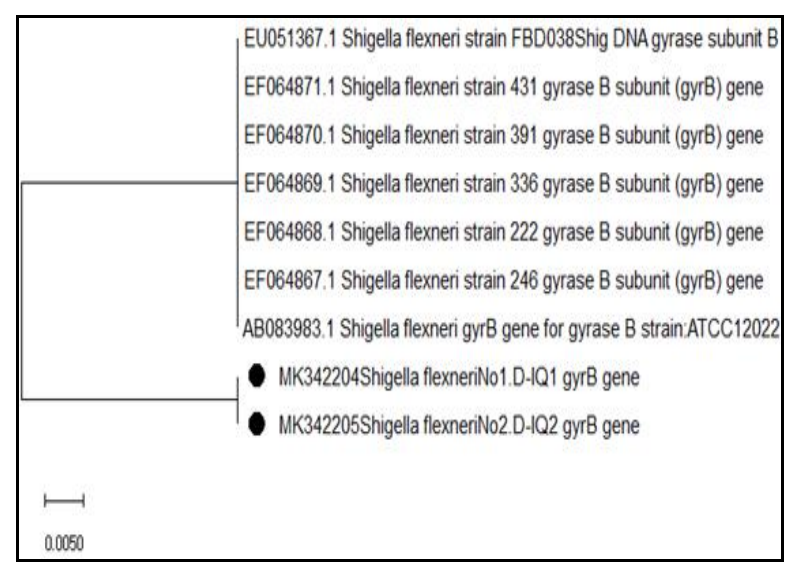

Figure 2: Phylogenetic tree image. Big black dots are the current study isolates.

\section{Discussion}

Shigella flexneri is a bacterium characterized by Gramnegative staining and its behaviour as a facultative anaerobe which is a member of the family, Enterobacteriaceae(Jin et al., 2002; Wei et al., 2003). Failure to introduce sufficient management of the infection may add some detrimental incidents that might prevent required recovery within normal times or might lead to lose life (Williams and Berkley, 2018). The disease initiated by these bacteria is well known for its million-based morbidity and mortality occurrence especially in children in poor-health system countries (Kotloff et al., 1999).The results in the current work revealed the presence of S.flexneri in the samples using the regular Lab techniques specific for the isolation of bacteria. These techniques are important in the isolation of bacteria providing vital primary detextion before heading to downstream molecular techniques, and this agrees with (Faruque et al., 2002) who isolated these microorganisms from water samples using these primary techniques. The current work results also agree with (Jomezadeh et al., 2014) who isolated Shigella species from dysentery samples of children in Iran using the primary lab techniques. Using PCR-based techniques, the present study identified and confirmed the presence of $S$. flexneri in the samples tested for this purpose. These are important techniques to support the validity of the primary, TBI, methods. These results agree with ( $\mathrm{Vu}$ et al., 2004) who used PCR in the detection of Shigella strains using ipaHas a target gene in Vietnam and suggested increasing prevalence of the disease in this country. The current work results also agree with (Ojha $e t$ al., 2013) who detected these bacteria using pentaplex PCR targeted 5 genes.Sequencing and the phylogenetic analyses revealed important identification and confirmation that supported the results obtained from the previous techniques used in the present study. These techniques reflect important information inferred by the phylogenetic analysis showing separate distinctive clustering of the sequenced samples in one branch of the phylogenetic tree, and this could indicate unique strains related to the current tested city (Fukushima etal., 2002). The current study enhances the documentation that $S$. flexneri is one of the infectious agents that causes GIT-related infections in the current tested city. 


\section{References}

Bennish, M. L. (1991) 'Potentially lethal complications of shigellosis.', Reviews of infectious diseases, $13 \mathrm{Suppl}$ 4, pp. S319-24.

Faruque, S. M.; Khan R.;, Kamruzzaman M.; Yamasaki, S.; Ahmad, Q. S.; Azim, T.; Nair G. B.; Takeda, Y. and Sack D. A. (2002) 'Isolation of Shigella dysenteriae type 1 and $\mathrm{S}$. flexneri strains from surface waters in Bangladesh: comparative molecular analysis of environmental Shigella isolates versus clinical strains.', Applied and environmental microbiology. American Society for Microbiology (ASM), 68(8), pp. 3908-13. doi: 10.1128/AEM.68.8.3908-3913.2002.

Fukushima, M., Kakinuma, K. and Kawaguchi, R. (2002) 'Phylogenetic analysis of Salmonella, Shigella, and Escherichia coli strains on the basis of the gyrB gene sequence.', Journal of clinical microbiology. American Society for Microbiology (ASM), 40(8), pp. 2779-85. doi: 10.1128/JCM.40.8.2779-2785.2002.

Hale, T. L. and Keusch, G. T. (1996) Shigella, Medical Microbiology. University of Texas Medical Branch at Galveston.

Jennison, A. V. and Verma, N. K. (2004) 'Shigella flexneri infection: pathogenesis and vaccine development', FEMS Microbiology Reviews. Oxford University Press, 28(1), pp. 43-58. doi: 10.1016/j.femsre.2003.07.002.

Jin, Q.; Yuan, Z.; Xu, J.; Wang Y., Shen Y., and et al. (2002) 'Genome sequence of Shigella flexneri 2a: insights into pathogenicity through comparison with genomes of Escherichia coli K12 and O157.', Nucleic acids research, 30(20), pp. 4432-41.

Jomezadeh, N.; Babamoradi, S.; Kalantar, E., and Javaherizadeh H.(2014) 'Isolation and antibiotic susceptibility of Shigella species from stool samples among hospitalized children in Abadan, Iran.', Gastroenterology and hepatology from bed to bench. Shahid Beheshti University of Medical Sciences, 7(4), pp. 218-23.

Kotloff, K. L.; Winickoff, J.P.; Ivanoff, B.; Clemens, J.D.; Swerdlow, D.L.; Sansonetti, P. J.; Adak, G.K. and. Levine M.M. (1999) Global burden of Shigella infections: implications for vaccine development and implementation of control strategies.

Lee, H. S.; Ha Hoang T. T.; Pham-Duc P.; Lee M. ; Grace D.; Phung D. C.; Thuc V.M. and Nguyen-Viet H. (2017) 'Seasonal and geographical distribution of bacillary dysentery (shigellosis) and associated climate risk factors in Kon Tum Province in Vietnam from 1999 to 2013', Infectious Diseases of Poverty. BioMed Central, 6(1), p. 113. doi: 10.1186/s40249-017-0325-z.

Ojha, S. C.; Yean, C. Y.; Ismail, A. and Singh K. B. (2013) 'A pentaplex PCR assay for the detection and differentiation of Shigella species.', BioMed research international. Hindawi Limited, 2013, p. 412370. doi: 10.1155/2013/412370.

Payne, S. M. and Finkelstein, R. A. (1977) 'Detection and differentiation of iron-responsive avirulent mutants on Congo red agar.', Infection and immunity, 18(1), pp. 94-8.

Saitou, N. and Nei, M. (1987) 'The neighbor-joining method: a new method for reconstructing phylogenetic trees.', Molecular Biology and Evolution, 4(4), pp. 406-25. doi: 10.1093/oxfordjournals.molbev.a040454.

Tamura, K.; Stecher, G.; Peterson, D.; Filipski, A. and Kumar S. (2013) 'MEGA6: Molecular Evolutionary Genetics Analysis Version 6.0', Molecular Biology and Evolution, 30(12), pp. 2725-2729. doi: 10.1093/molbev/mst197.

Taneja, N. and Mewara, A. (2016) 'Shigellosis: Epidemiology in India.', The Indian journal of medical research. Wolters Kluwer -- Medknow Publications, 143(5), pp. 565-76. doi: 10.4103/0971-5916.187104.

Turbyfill, K. R., Hartman, A. B. and Oaks, E. V (2000) 'Isolation and characterization of a Shigella flexneri invasin complex subunit vaccine.', Infection and immunity. American Society for Microbiology (ASM), 68(12), pp. 6624-32.

Vu, D. T.; Sethabutr, O.; Seidlein, L.; Tung, T. V.; Canh, D. G., and et al. (2004) 'Detection of Shigella by a PCR assay targeting the ipaH gene suggests increased prevalence of shigellosis in Nha Trang, Vietnam.', Journal of clinical microbiology. American Society for Microbiology (ASM), 42(5), pp. 2031-5. doi: 10.1128/JCM.42.5.2031-2035.2004.

Wei, J.; Goldberg, M. B.; Burland, V.; Venkatesan, M. M.; Deng, W., and et al. (2003) 'Complete genome sequence and comparative genomics of Shigella flexneri serotype $2 \mathrm{a}$ strain 2457T.', Infection and immunity, 71(5), pp. 2775-86.

Williams, P. C. M. and Berkley, J. A. (2018) 'Guidelines for the treatment of dysentery (shigellosis): a systematic review of the evidence.', Paediatrics and international child health. Taylor \& Francis, 38(sup1), pp. S50-S65. doi: 10.1080/20469047.2017.1409454.

Yamamoto, S. and Harayama, S. (1995) 'PCR amplification and direct sequencing of gyrB genes with universal primers and their application to the detection and taxonomic analysis of Pseudomonas putida strains. Applied and environmental microbiology, 61(3), $\quad$ pp. 1104-9. 